\title{
MiR-133b Promotes Neurite Outgrowth by Targeting RhoA Expression
}

\author{
Xiao Cheng Lu Jin Yu Zheng ${ }^{a, b}$ Lin Jun Tang ${ }^{a}$ Bao Sheng Huang ${ }^{a, c} \quad K a i$ Li $^{a}$ \\ $\mathrm{Yi} \mathrm{Tao}^{\mathrm{a}}$ Wan Yu${ }^{\mathrm{a}}$ Rong Lan Zhu ${ }^{\mathrm{a}}$ Shuai Lia $\mathrm{Li}^{\mathrm{Xin} \mathrm{Li}^{\mathrm{a}}}$
}

aDepartment of Neurosurgery, First Affiliated Hospital of Nanjing Medical University, Nanjing, bDepartment of Neurosurgery, The Affiliated Huai'an Hospital of Xuzhou Medical College, Huai'an, 'Department of Neurosurgery, Sir Run Run Shaw Hospital, Nanjing Medical University, Nanjing, China

\section{Key Words}

Mir-133b • Neurite $・$ RhoA $\cdot$ ERK1/2 $・$ Akt

\begin{abstract}
Background: MicroRNA-133b (miR-133b) has been shown to play a critical role in spinal cord regeneration. The aim of this study was to investigate the cellular role of miR-133b in neural cells. Methods: PC12 cells and primary cortical neurons (PCNs) were transfected with lenti-miR-133b, lenti-miR-133b inhibitor, plasmid-shRNA-RhoA, plasmid-RhoA and their negative controls. After 48 hours of transfection, the levels of proteins and mRNA or miRNA were evaluated by Western blotting and GRT-PCR, respectively. Moreover, the neurite outgrowth was analyzed by Image J. For pharmacological experiments, inhibitors of MEK1/2 kinase (PD98059), phosphoinositide-3' kinase (PI3K) (LY294002) and ROCK (Y27632) were added into the culture medium. Results: Overexpression of miR-133b in PC12 cells enhanced neurite outgrowth. Conversely, inhibition of miR-133b reduced neurite length. We further identified RhoA as a target and mediator of mir-133b for neurite extension by Western blot and knockdown experiment. Moreover, overexpression of RhoA could attenuate the neurite growth effects of miR-133b. Also, we observed that miR-133b activated MEK/ERK and PI3K/Akt signaling pathway by targeting RhoA. Finally, in PCNs, miR-133b also increased axon growth and attenuated axon growth restrictions from chondroitin sulfate proteoglycans (CSPG). Conclusions: In summary, our study suggested that miR-133b regulated neurite outgrowth via ERK1/2 and PI3K/Akt signaling pathway by RhoA suppression.
\end{abstract}




\section{Cellular Physiology and Biochemistry}

Cell Physiol Biochem 2015;35:246-258

\begin{tabular}{l|l}
\hline DOI: $10.1159 / 000369692$ & (C) 2015 S. Karger AG, Basel
\end{tabular}

\begin{tabular}{l|l} 
Publisned online: January 09, 2015 & www.karger.com/cpb
\end{tabular}

Lu et al.: MiR-133b Promotes Neurite Outgrowth

\section{Introduction}

MicroRNAs (miRNAs) are a class of endogenous small non-coding RNAs with a length of 19-23 nucleotides. The mature miRNAs recognizes complementary sites in the 3'UTR of their corresponding target genes, resulting in down-regulation of a wide variety of proteins. [1] During development, numerous miRNAs have been shown to be involved in neurogenesis and neuronal maturation in the central nervous system (CNS) [2]. Moreover, accumulated studies provided evidence that miRNAs also appeared to play important roles in axon extension and branching, such as miR-9, miR-34a and miR-124 [3-5].

MiR-133b is a commonly dys-regulated miRNA in numerous forms of cancer, including lung cancer, gastrointestinal cancer, and prostate cancer [6-8]. It has been reported that miR-133b was also a key regulator of cardiac hypertrophy by targeting RhoA and Cdc42. [9] In CNS, miR-133b is enriched in the midbrain and plays an important role in differentiation and degeneration of midbrain dopaminergic neurons through repressing Pitx3, a paired-like homeodomain transcription factor $[10,11]$. Moreover, recent studies showed that miR-133b was implicated in the functional recovery of spinal cord injury and stroke [12-14], while the cellular role of miR-133b in neurite outgrowth of neural cells remained unclear.

PC12 cells, a cell line from the rat pheochromocytoma of the adrenal medulla, have been extensively used as a mature neural cell model of neurite outgrowth with nerve growth factor (NGF) treatment [15]. NGF stimulates neurite outgrowth of PC12 cells by activating numerous intracellular signaling pathways, including mitogen-activated protein kinase (MAPK) pathway, phosphatidylinositol 3-kinase (PI3-K)/Akt, cAMP pathway, and RhoA/ROCK pathway. In this study, we aimed to investigate the role of miR-133b in neurite extension in PC12 cells and primary cortical neurons (PCNs). The results indicated that manipulation of miR-133b expression was associated with neurite outgrowth in PC12 cells. Briefly, overexpression of miR-133b suppressed RhoA expression and activated PI3K/Akt and ERK1/2 pathways, thereby promoting neurite outgrowth. Moreover, we showed that miR-133b was able to reverse the inhibitory effect of chondroitin sulfate proteoglycans (CSPG) on axon regeneration in PCNs.

\section{Materials and Methods}

\section{Animals}

The laboratory animals used in all experimental procedures were provided by the Department of Animal Experiments, Nanjing Medical University. Animal studies were approved by the Animal Experimental Committee of the Nanjing Medical University and the procedures complied with relevant laws.

\section{PC12 Cell culture}

PC12 cells (purchased from the Type Culture Collection of the Chinese Academy of Sciences, Shanghai, China) (passage number $<10$ ) were cultured at $37^{\circ} \mathrm{C}, 5 \% \mathrm{CO}_{2}$ in Roswell Park Memorial Institute (RPMI) 1640 medium (Life Technologies, USA) supplemented with $10 \%$ heat-inactivated horse serum, $5 \%$ fetal bovine serum (FBS) (Life Technologies, USA), and $100 \mathrm{U} / \mathrm{ml}$ penicillin/streptomycin (Beyotime Institute of Biotechnology, China). The medium was changed every 3 days. For neurite outgrowth experiments, PC12 cells were plated at a density $5 \times 10^{3}$ cells $/ \mathrm{cm}^{2}$ on 24 -well tissue culture plates coated with ploy-l-lysine.

\section{PCNs culture}

PCNs were prepared from embryonic Sprague-Dawley day 18 rats as previously described [16, 17]. Briefly, pregnant SD rats at day 18 of gestation were euthanized and embryos were harvested in sterile conditions. After removing of the meninges under microscope, the cerebral cortex was collected in Hanks' solution without $\mathrm{Ca}^{2+}$ and $\mathrm{Mg}^{2+}$ (D-Hanks) (Life Technologies, USA) and then transferred to trypsin-EDTA (Life Technologies, USA) (0.125\% in D-Hanks' solution) incubation for $15 \mathrm{~min}$ at $37{ }^{\circ} \mathrm{C}$. After stopping trypsinization with $20 \%$ FBS, the cells were mechanical triturating in DMEM/F-12 (HyClone, USA) with $10 \%$ FBS, and further centrifuged for 5 minutes at $1000 \mathrm{r} / \mathrm{min}$. Finally, the cells were resuspended in 


\section{Cellular Physiology and Biochemistry}

Cell Physiol Biochem 2015;35:246-258

\begin{tabular}{l|l}
\hline DOI: $10.1159 / 000369692$ & (c) 2015 S. Karger AG, Basel
\end{tabular}

Published onine: January 09, $2015 \quad$ www.karger.com/cpb

Lu et al.: MiR-133b Promotes Neurite Outgrowth

the neurobasal medium (Life Technologies, USA) containing 2\% B27 (Life Technologies, USA), 0.5 mM L-glutamine (Life Technologies, USA) and $50 \mathrm{U} / \mathrm{ml}$ penicillin/streptomycin and plated on poly-L-lysinecoated 24-well or 6-well plates at a density of $2 \times 10^{5} \mathrm{cells} / \mathrm{ml}$. The medium was replaced with fresh medium every 3 days. A pilot study using immunocytochemistry revealed that over $95 \%$ of the cells were positive for the neuronal marker MAP2.

\section{Cell transfection and lentivirus infection}

Lentivirus and plasmid transfection of PC12 cells or PCNs were performed as previously reported [18]. Briefly, the vector of lenti-miR-133b or lenti-miR-133b-inhibitor contained a coral GFP or RFP gene for tracking transfection efficiency, which driven by CMV promoter. The plasmid vector of RhoA-specific shRNA (shRhoA) or RhoA cDNA contained a neomycin resistance gene for establishing a stable cell line and RFP gene (or YFP gene for RhoA cDNA) for tracking transfection efficiency, driven by the SV40 promoter and CMV promoter, respectively. PC12 cells were transfected with plasmids by using Lipofectamine 2000 following the manufacturer's instructions. For lentivirus infections, $2 \times 10^{4} \mathrm{PC} 12$ cells or $1 \times 10^{5} \mathrm{PCNs}$ were exposed to $1 \times 10^{6}$ virus particles for 12 hours. Twenty four hours after transfection, PC12 cells were differentiated for 48 hours with NGF (100ng/ml, Sigma-Aldrich, USA) In some experiments, the cells were also cultured with LY294002 (10uM, an inhibitor of PI3K) (Sigma-Aldrich, USA), or PD098059 (10uM, an inhibitor of MAP kinase (MAPK) kinase, MEK1) (Sigma-Aldrich, USA).

\section{Measurement of neurite outgrowth}

Two days after NGF treatment, cells were visualized by a fluorescence microscope. Effectively transfected PC12 cells were identified by expression of GFP, RFP or YFP. Cells extending at least one neurite with a length longer than the cell body diameter were measured as positive neurite-bearing cells as previously described. $[19,20]$ The average neurite length was measured for all neurite-bearing cells in a field by tracing the longest neurite length per effectively transfected cell using Image J software. To assess the longest neurite length, the 5 longest neurites in each experiment were measured and were averaged to yield a single value for each well [21]. Neurite outgrowth was measured on an average of 400 effectively transfected cells per experiment and each experiment was repeated three times.

For neurite inhibition experiments, PCNs were plated in 24-well plates coated with poly-l-lysine or CSPG substrates. Cells were then transfected with lenti-miR-133b/lenti-miR-NC or treated with 50 uM Y27632 (an inhibitor of RhoA/ROCK pathway) (Sigma-Aldrich, USA). CSPG substrates were made as previously described, by incubating $0.5 \mathrm{ug} / \mathrm{ml}$ mixed chondroitin sulfate proteoglycan (CSPG) solution (Merck Millipore, Germany) overnight in poly-l-lysine coated plates [22]. For neurite length assessment, the longest neurite per neuron was measured on an average of 400 effectively transfected cells per experiment with a minimum of three experiments per condition.

\section{Quantitative real-time reverse transcription polymerase chain reaction ( $q R T-P C R$ )}

Total RNA was extracted from cultured cells using Trizol Reagent (Life Technologies, USA) following the manufacturer's instructions. RNA samples were quantitated using Biophotometer (Eppendorf, Germany). Reverse-transcribed complementary DNA (using stem loop specific primers for miRNA detection) was synthesized with the Prime-Script RT reagent Kit (TaKaRa, China). In addition, quantitative real-time PCR (RT-PCR) was performed using the miScript SYBR Green PCR Kit in 96-well plates according to the manufacturer's protocol using an Applied Biosystem 7500 apparatus. The relative expression levels of miRNA and mRNA were calculated according to the $\Delta \Delta$ Ct method and normalized by U6 small nucleolar RNA and GAPDH mRNA levels, respectively. Three data points were used and the experiment was replicated in three times.

\section{MTT assay}

Proliferation of PC12 cells was assessed by the MTT assay [23]. Briefly, PC12 cells transfected with lenti-miR-133b or lenti-miR-NC were seeded in 96-well plates at a density of $1 \times 10^{5}$ and incubated overnight. Cells were then incubated with $20 \mu \mathrm{l}$ MTT $\left(5 \mathrm{mg} / \mathrm{ml}\right.$, Sigma-Aldrich, USA) for $4 \mathrm{~h}$ at $37^{\circ} \mathrm{C}$. After washed twice with PBS, formazan products in the cells were dissolved by dimethyl sulfoxide (DMSO, SigmaAldrich, USA) with plate shaking for $10 \mathrm{~min}$. The absorbance was measured at a test wavelength of $570 \mathrm{~nm}$ and a reference wavelength of $630 \mathrm{~nm}$. The results were expressed as percentage of the control group. 


\section{Cellular Physiology and Biochemistry}

Cell Physiol Biochem 2015;35:246-258

\begin{tabular}{l|l}
\hline DOI: $10.1159 / 000369692$ & (C) 2015 S. Karger AG, Basel
\end{tabular}

\begin{tabular}{l|l} 
Publisned oniline: January 09, 2015 & www.karger.com/cpb
\end{tabular}

Lu et al.: MiR-133b Promotes Neurite Outgrowth

Terminal deoxynucleotidyl transferasemediated biotinylated UTP nick end labeling (TUNEL) staining

Apoptosis in PC12 cells transfected with lenti-miR-133b or lenti-miR-NC was detected using the TiterTACS In Situ Detection Kit (R\&D systems, USA) according to the manufacturer's instructions. PC12 cells planted in the 96 well plates were fixed with 3.7\% Buffered Formaldehyde solution for 7 min. Cells were then incubated in 100\% methanol for 20 minutes at room temperature. After incubation with Proteinase $\mathrm{K}$ for 15 min, PC12 cells were treated with peroxide solution for 5 min to quench endogenous peroxidase. Next, cells were labeled with TdT Enzyme for $1 \mathrm{~h}$ at $37^{\circ} \mathrm{C}$ and then treated with stop buffer. The cells were incubated with Streptavidin-HRP for $1 \mathrm{~h}$, and absorbance was measured on a microplate reader at a wavelength of $450 \mathrm{~nm}$. In addition, TACS-Nuclease was used to generate positive control, and the negative controls were labeled without TdT Enzyme.

Immunocytochemistry

Neurons cultured in 24-well plates were fixed with 4\% paraformaldehyde for 20 min and washed 3 times in PBS. Following permeabilization with $0.1 \%$ TritonX-100 (Sigma-Aldrich, USA) for 10 min, cells were blocked with 5\% BSA (Sigma-Aldrich, USA) for $30 \mathrm{~min}$. Cells were then incubated with primary antibody microtubule-associated protein-2 (MAP-2) (1:500, Abcam, UK) or Tuj1 (1:1000, Abcam, UK) overnight at $4{ }^{\circ} \mathrm{C}$, followed by incubation with the $\mathrm{Cy} 3(1: 500$, Abcam, UK) conjugated secondary antibody for $1 \mathrm{~h}$ at room temperature. Cells were imaged using a fluorescence microscope and analyzed by Image Pro Plus software.

Western blotting

Total protein from cells was extracted with RIPA lysis buffer (Beyotime Institute of Biotechnology, China) supplemented with $1 \%$ protease inhibitor (GeneChem, China) and 1\% phosphatase inhibitor (GeneChem, China). Western blotting was performed according to protocols. Briefly, an equivalent amount of cellular protein (20ug) was separated by 10\% SDS-PAGE, and transferred to PVDF membranes (Merck Millipore, Germany). After blocking with 5\% non-fat dry milk for $2 \mathrm{~h}$ at room temperature, the membranes were incubated with primary antibody, including p-Akt (1:2000, Cell Signaling Technology, USA), total Akt (1:1000, Cell Signaling Technology, USA), p-p38 (1:1000, Cell Signaling Technology, USA), total p38 (1:1000, Cell Signaling Technology, USA), p-ERK1/2 (1:1000, Cell Signaling Technology, USA), total ERK1/2 (1:1000, Cell Signaling Technology, USA), RhoA (1:1000, Cell Signaling Technology, USA), GAPDH (1:2000, Cell Signaling Technology, USA), and $\beta$-actin (1:5000; Bioworld Technology Inc, China) at $4{ }^{\circ} \mathrm{C}$ overnight. The membranes were then incubated in goat anti-rabbit IgG antibody conjugated to horseradish peroxidase (1:5000, Bioworld Technology Inc, China) at room temperature for $1 \mathrm{~h}$. Finally, bands were measured by the enhanced chemiluminescent system ECL Plus (Thermo Scientific, USA) Relative levels of protein were quantified by optical density analysis using Image Lab (Version 2.0.1). Three bands were quantified per experiment and each experiment was replicated at least 3 times.

Statistical Analysis

Data are presented as mean \pm SD of three independent experiments. Student's t-test for unpaired variables was used to determine statistical significance of differences between groups, and a P-value less than 0.05 was considered statistically significant.

\section{Results}

MiR-133b promoted neurite outgrowth in PC12 cells

To investigate whether miR-133b regulates neurite outgrowth, PC12 cells were transfected with lenti-miR-133b or lenti-miR-NC. The overexpression of miR-133b was verified by real-time PCR analysis (Fig. 1A) and the neurite length was detected as described above. The results showed that miR-133b enriched PC12 cells extended a significant increase in neurite extension than those transfected with miR-NC, both in average neurite length $(120.81 \pm 21.36 \mathrm{um}$ vs $81.88 \pm 18.60 \mathrm{um})$ and longest neurite length $(230.91 \pm 33.56 \mathrm{um}$ vs $163.20 \pm 16.74 \mathrm{um}$ ) (Fig. 1B and 1D). We further examined whether knockdown of miR-133b inhibited the neurite extension. PC12 cells transfected with lenti-miR-133b inhibitor, which 
Fig. 1. Overexpression of miR-133b promoted neurite outgrowth in PC12 cells. A) q-RT PCR indicated transfection of lenti-mi R-133b significantly increased miR133b expression in PC12 cells; B) representative live cell images of PC12 cells transfected with lentimiR-133b or lenti-miR-NC and treated with $(+)$ or without (-) NGF; C) expression of miR-133b in PC12 cells treated with (+) or without $(-)$ NGF after 24 or 48 hours; D) quantification of average and longest nerite length from three indepen-
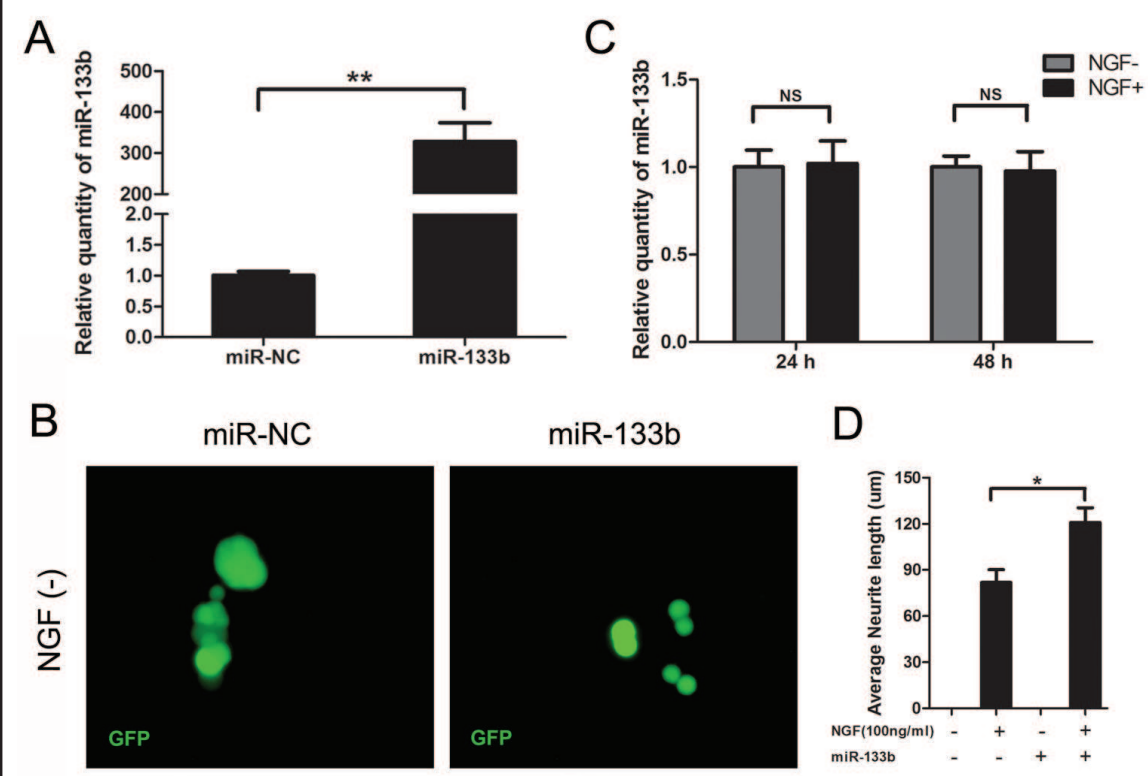

D
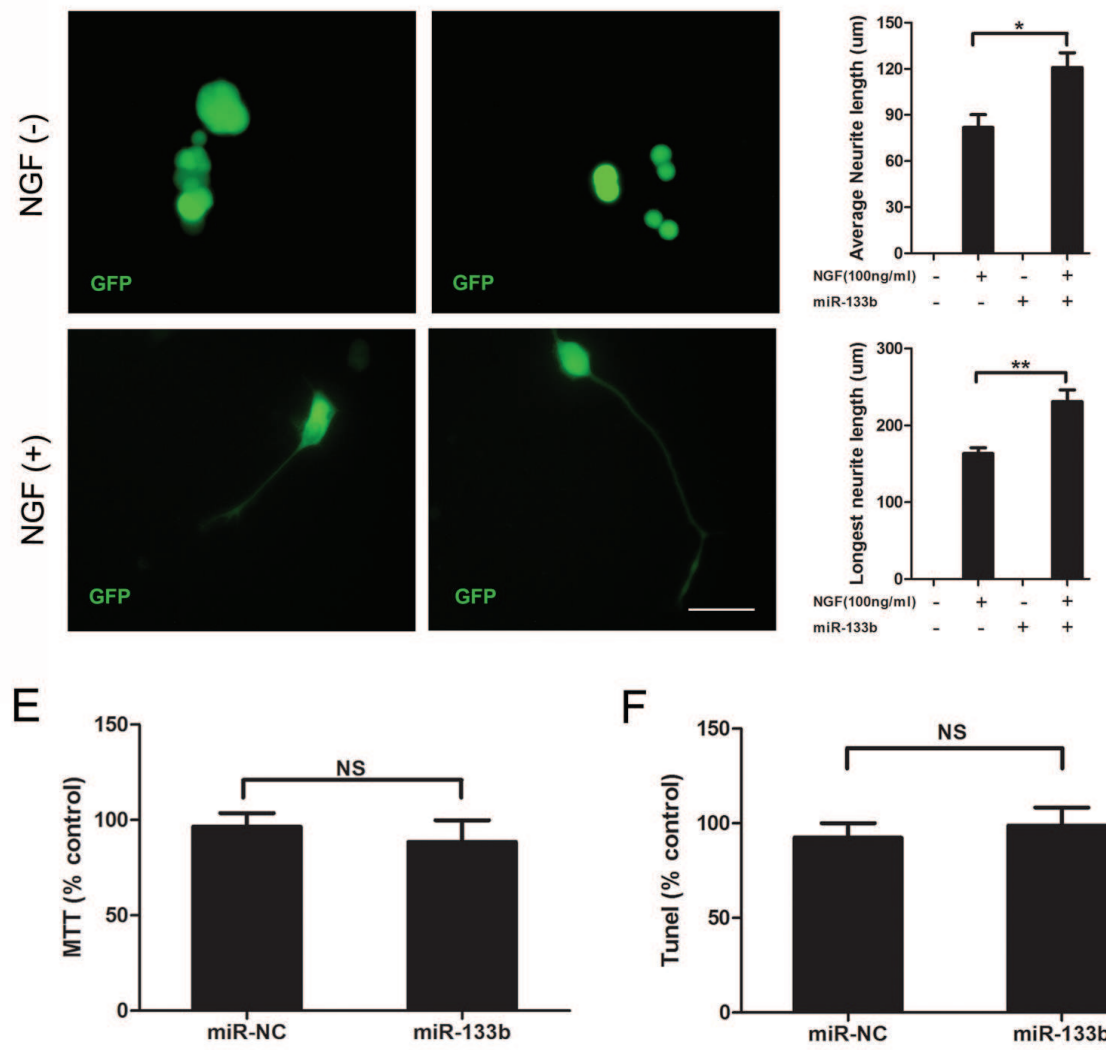

F

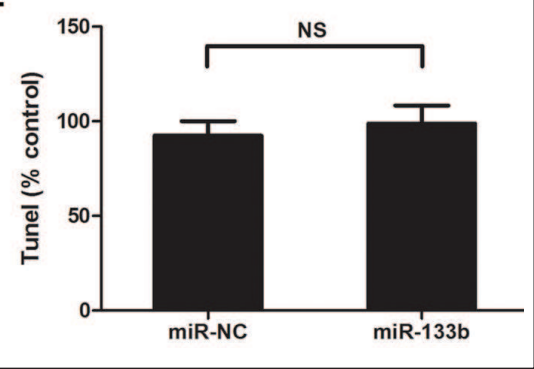

dent experiments; E) The cell proliferation in PC12 cells transfected with lenti-miR-133b or lenti-miR-NC was assessed by MTT assay; F) The cell apoptosis in PC12 cells transfected with lenti-miR-133b or lentimiR-NC was detected by TUNEL assay. $\left({ }^{*} \mathrm{p}<0.05,{ }^{* *} \mathrm{p}<0.01\right.$, NS: non-significant, bar $\left.=50 \mathrm{um}\right)$.

could suppress mature miR-133b expression (Fig. 2A), exhibited a significant decrease in neurite length (Fig. 2B and 2C) (57.56 \pm 13.10 um vs $85.97 \pm 15.11 \mathrm{um})$.

\section{MiR-133b did not contribute to neural differentiation in PC12 cells}

To identify whether miR-133b is involved in NGF-induced neural differentiation, we isolated total RNA from PC12 cells untreated or treated with NGF for 24 or 48 hours. The results of qRT-PCR showed that expression of miR-133b did not alter between two groups. (Fig. 1C) Moreover, in the absence of NGF, overexpression of miR-133b had no effect on neural differentiation in PC12 cells (Fig. 1B and 1D). Also, we showed that overexpression of miR133b had no effect on cell proliferation and apoptosis by using MTT and TUNEL assay. (Fig. $1 \mathrm{E}$ and $1 \mathrm{~F}$ ) Together, these results suggested that miR-133b mediated neurite outgrowth but not neural differentiation in PC12 cells. 


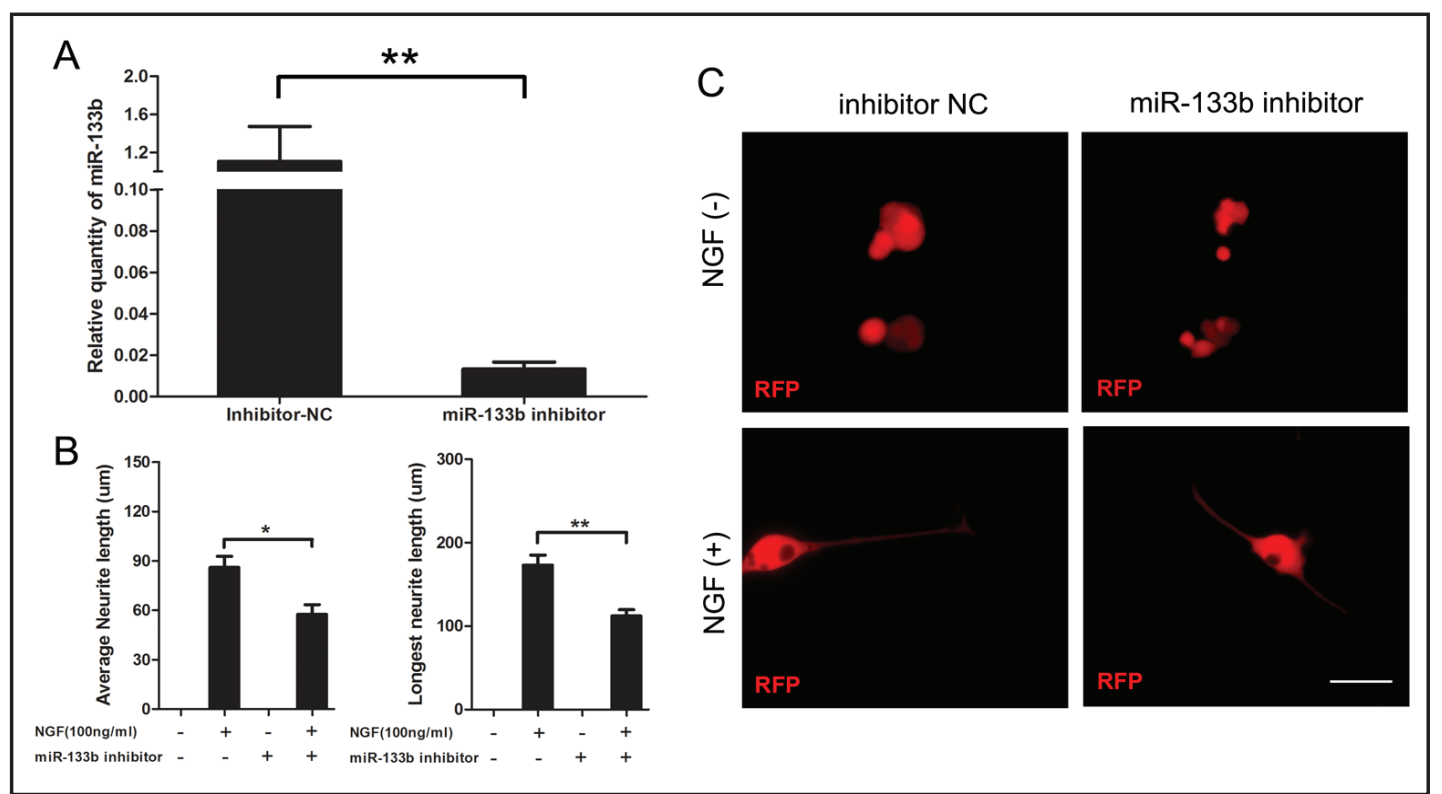

Fig. 2. Inhibition of miR-133b decreased neurite outgrowth in PC12 cells. A) expression of miR-133b in PC12 cells transfected with lenti-miR-133b inhibitor or lenti-inhibitor-NC; B) quantification of average and longest nerite length $\mathrm{C}$ ) representative live cell images of PC12 cells transfected with miR-133b inhibitor or inhibitor-NC and/or treated with (+) or without (-) NGF. $\left({ }^{*} \mathrm{p}<0.05,{ }^{* *} \mathrm{p}<0.01\right.$, bar $\left.=50 \mathrm{um}\right)$.

\section{MiR-133b inhibited RhoA expression}

Previous studies confirmed that several mRNA were targets of miR-133b, such as Foxl2, MST2, and RhoA [9, 24, 25]. RhoA, a small GTPase, has been shown to play a critical role in axon growth $[26,27]$. In this study, Western blot analysis indicated that expression of RhoA was significant decreased in miR-133b enriched PC12 cells, whereas inhibitors of miR-133b elevated RhoA level (Fig. 3A). In addition, real-time RT-PCR demonstrated that the mRNA of RhoA was not affected following modulation of miR133b (Fig. 3B).

We then investigated the functional effect RhoA on neurite outgrowth in PC12 cells by transfection with a plasmid-shRhoA or a control plasmid. Western blot confirmed that shRhoA significantly reduced expression of RhoA in PC12 cells after 48 hours. (Fig. 5) Moreover, shRhoA substantially facilitated neurite outgrowth in PC12 cells similar to that induced by miR-133b (Fig. 3C).

To further validate the role of RhoA in miR-133b mediated neurite outgrowth, we transduced PC12 cells with lenti-miR-133b and plasmid-YFP-RhoA (pYFP-RhoA). The result showed that transfection of pYFP-RhoA evaluated RhoA expression and was sufficient to reduce miR-133b induced neurite outgrowth. However, transduction of lenti-miR-133b and plasmid-YFP (pYFP) showed a significant increase in neurite outgrowth as previously described (Fig. 3D). Together, these data suggested that RhoA played a critical role in the neurite outgrowth induced by miR-133b in PC12 cells.

\section{MiR-133b activated ERK1/2 and PI3K/Akt pathways}

We next investigated what signaling pathway was responsible for miR-133b induced neurite extension. Several signaling pathways have been shown to play important roles in neurite outgrowth in PC12 cells, including mitogen-activated protein kinase (MAPKs) classes and phosphoinositide 3-kinase (PI3K) $[28,29]$. Here, we showed that phosphorylation of Erk1/2 and Akt (Ser473) in miR-133b overexpressed cells was significantly higher than that in miR-NC group, whereas activation of p38 was not different between two groups (Fig. 4A). Moreover, PD98059 and LY294002 strongly inhibited neurite growth induced by miR-133b in PC12 cells. PD98059 also inhibited the neurite outgrowth in lenti-miR-NC transfected PC12 cells, which was not observed in PC12 cells treated with LY294002. (Fig. 4B) Also, we 


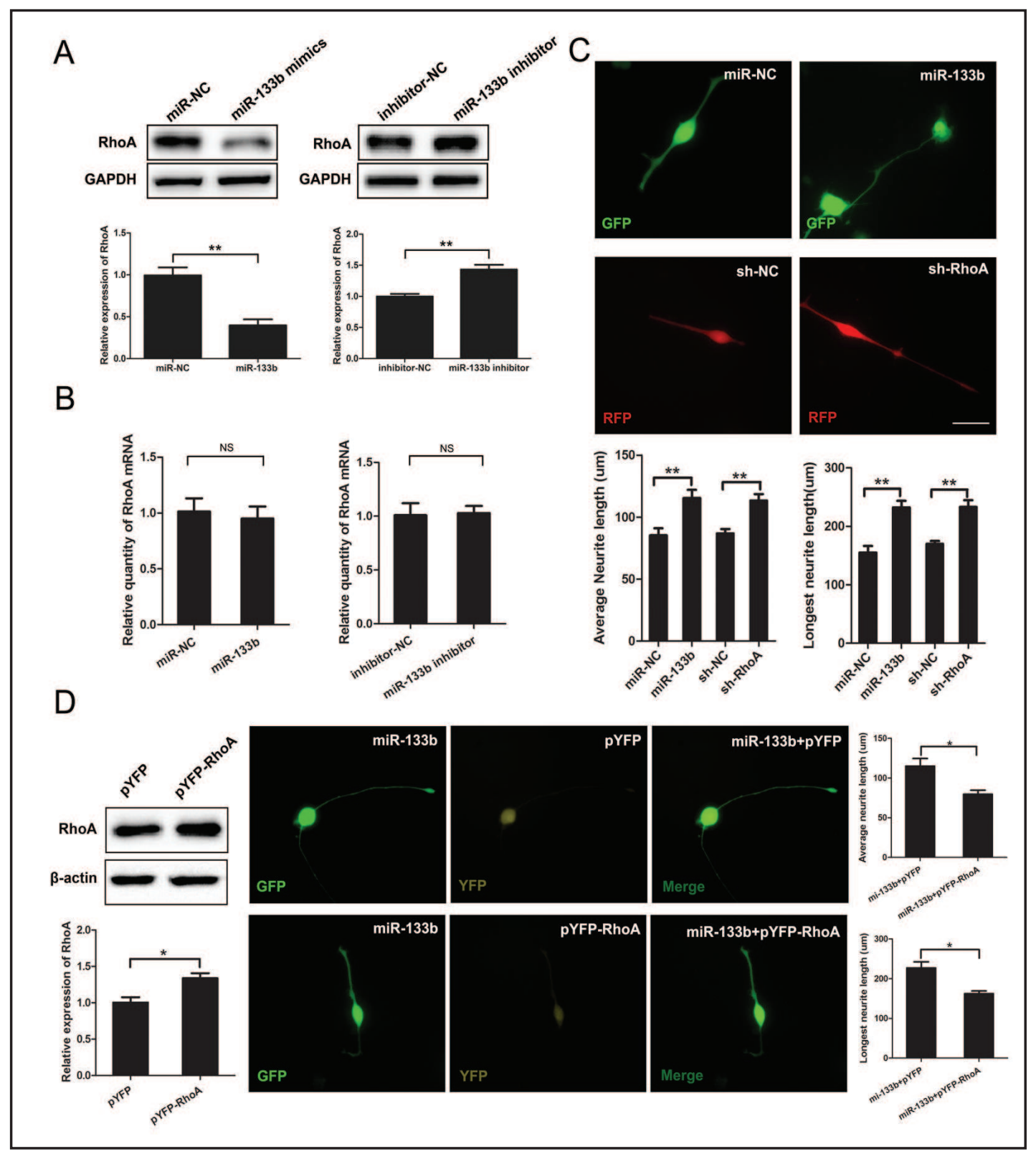

Fig. 3. MiR-133b targets RhoA. A) Western blot analysis of RhoA in PC12 cells transfected with lentimiR-133b, lenti-miR-NC, lenti-miR-133b inhibitor or lenti-inhibitor-NC; B) expression of mRNA of RhoA in PC12 cells transfected with lenti-miR-133b, lenti-miR-NC, sh-RhoA or sh-NC; C) representative live cell images of PC12 cells transfected with lenti-miR-133b, lenti-miR-NC, sh-RhoA or sh-NC; D) Western blot analysis of RhoA in PC12 cells transfected with pYFP-RhoA or pYFP; representative live cell images of PC12 cells co transfected with lenti-miR-133b and pYFP-RhoA or pYFP. $\left({ }^{*} \mathrm{p}<0.05\right.$, ${ }^{* *} \mathrm{p}<0.01$, NS: non-significant, bar=50um).

observed that inhibition of miR-133b significant decreased the phosphorylation of Erk1/2 and Akt (Fig. 4C).

MiR-133b activated ERK1/2 and PI3K/Akt pathway by targeting RhoA

Previous study demonstrated that inhibition of RhoA expression enhanced the phosphorylation of Erk1/2 and Akt [30,31]. In the presentstudy, we observed that knockdown of RhoA expression enhanced phosphorylation of Erk1/2. In addition, phosphorylation of Akt 
Fig. 4. MiR-133b activated ERK1/2 and Akt pathway. A) Western blot analysis of p-Akt/ Atk, p-Erk/Erk, and p-p38/p38 in PC12 cells ransfected with lenti-miR133b or lenti-miR$\mathrm{NC}$; B) representative live cell images of PC12 cells transfected with miR$133 \mathrm{~b}$ or miR-NC and in the absence or prescence of the specific MAPK-inhibitors PD98059 (10 uM) or PI3K inhibitor LY294002 (10 uM); C) Western blot analysis of p-Akt/Atk and p-Erk/Erk in PC12 cells ransfected with lenti-miR133b inhibitor or its negative control. $\left({ }^{*} \mathrm{p}<0.05,{ }^{* *} \mathrm{p}<0.01\right.$, NS: non-significant, bar=50um).

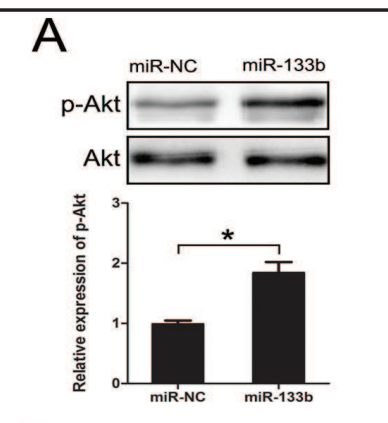

B
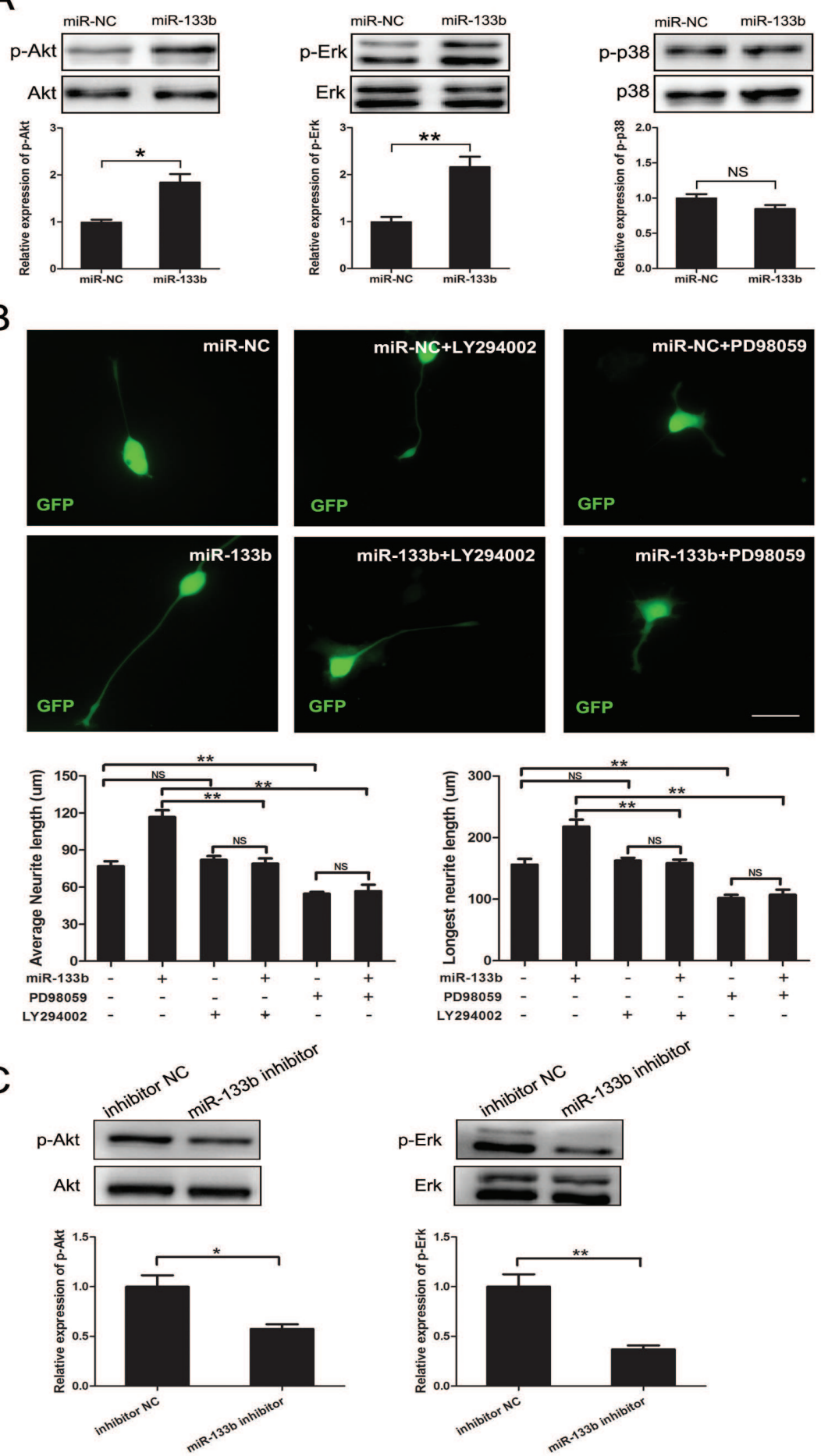

in PC12 cells was also increased, similar to that induced by miR-133b (Fig. 5). Together, these results suggested that miR-133b promoted the neurite extension might through activating of Erk1/2 and Akt pathway by targeting RhoA expression.

miR-133b stimulated primary cortical neurons axon outgrowth on normal and inhibitory substrates

We then investigated whether miR-133b has a similar effect on neurite elongation in primary neurons. PCNs were isolated from embryonic rats and the proportion of neurons KARGER 


\section{Cellular Physiology and Biochemistry}

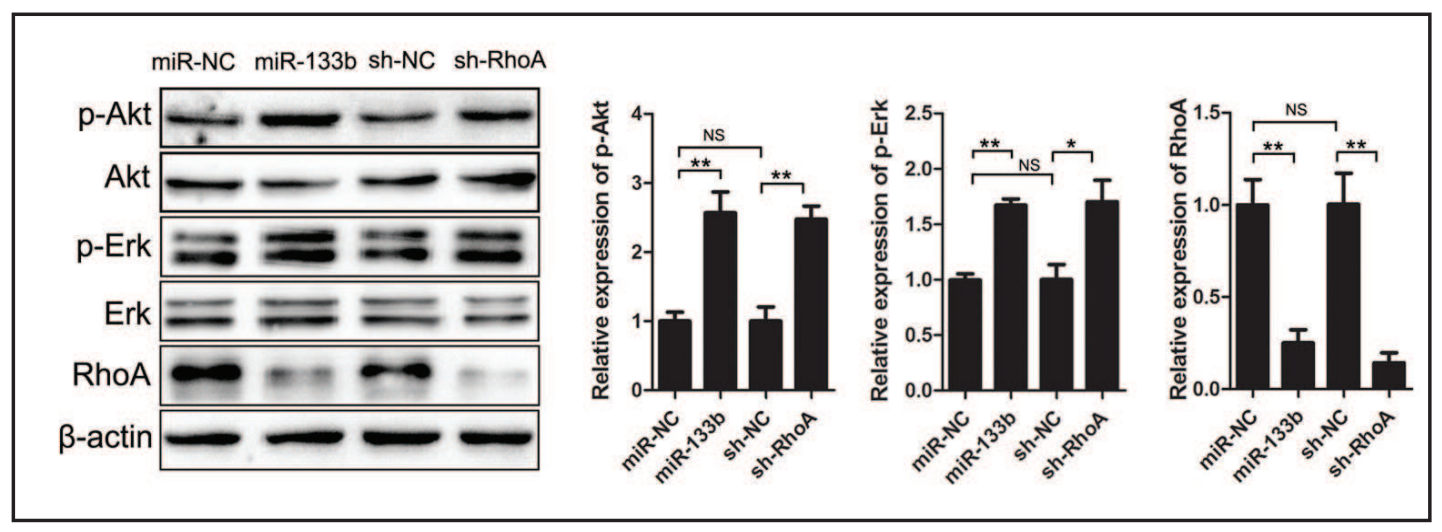

Fig. 5. MiR-133b activated ERK1/2 and Akt pathwayby targeting RhoA. (A) Expression of p-Akt, Atk, p-Erk, Erk, RhoA and $\beta$-actin in PC12 cells transfected with lenti-miR-133b, lenti-miR-NC, sh-RhoA or sh-NC. (B) Comparability was achieved by normalizing on total-Atk1/2, total-Erk1/2, total-p38, and $\beta$-actin levels. $\left({ }^{*} \mathrm{p}<0.05,{ }^{* *} \mathrm{p}<0.01, \mathrm{NS}\right.$ : non-significant $)$.

was about 95\%, which was indicated by positive staining for the neuronal marker MAP-2 (Fig. 6A). The results showed that overexpression of miR-133b decreased the protein levels of RhoA in PCNs, but had no effect on the expression of RhoA mRNA (Fig. 6B). Moreover, 3 days after transfection, we observed that miR-133b enriched PCNs extended longer axons than PCNs transfected with miR-NC. (98.70 \pm 11.88 um vs $64.87 \pm 9.68$ um) (Fig. 6C).

RhoA/ROCK pathway has been shown to play an important role in neurite growth inhibition from CSPG after CNS injury. To determine whether suppression of RhoA by miR$133 \mathrm{~b}$ can surmount axon growth restrictions from CSPG via RhoA/ROCK pathway, Y27632, an inhibitor of ROCK (one of the downstream targets of RhoA kinase), was employed. Consistent with previous report, CSPG dramatically inhibited neurite growth of PCNs. However, miR133b reversed the inhibitory effect of CSPG on neurite extension similar to Y27632 (Fig. 6D).

\section{Discussion}

It has been reported that miR-133b was highly expressed in the spinal cord immediately after traumatic injury [13]. Moreover, miR-133b has been shown to implicate in the functional recovery of spinal cord injury and stroke, whereas its cellular role is not fully understood $[12,14]$. In this study, we demonstrated that miR-133b regulated neurite outgrowth via MEK/ERK1/2 and PI3K/Akt pathways by RhoA supression. In PC12 cells, overexpression of miR-133b enhanced neurite extension. To further support the role of miR-133b in neurite outgrowth, we investigated the effect of miR-133b inhibition, which showed that blocking endogenous miR-133b function significantly reduced neurite outgrowth. Moreover, previous studies showed that NGF modulated the expression of a variety of microRNAs, such as miR21, which acted as an enhancer of NGF signaling [32]. Thus, we further explored whether miR-133b was involved in the neuronal differentiated induced by NGF, whereas the results of real time RT-PCR showed NGF stimulation did not alter the expression of miR-133b in PC12 cells. Additionally, in the absence of NGF, miR-133b alone could not induce neuronal differentiation in PC12 cells. These results suggested miR-133b mediated neurite outgrowth but not neural differentiation in PC12 cells.

Recent studies confirmed that several mRNAs were the direct targets of miR-133b, such as Foxl2, MST2, and RhoA [9, 24, 25]. Among these target genes, RhoA plays an important role in neuronal growth, which negatively regulates axon elongation and branching [33]. In this study, we observed that expression of RhoA was decreased after overexpression of miR$133 \mathrm{~b}$ and increased following miR-133b inhibition, paralleling with the neurites outgrowth. To further investigate the effect of RhoA on neurite extension in PC12 cells, RhoA-specific shRNA was transfected into PC12 cells. The shRhoA successfully suppressed RhoA expression 
Fig. 6. miR-133b promoted axon regeneration of primary cortical neurons. A) PCNs were immunostained with MAP2 and DAPI; (bar=100 um) B) protein and mRNA levels of RhoA in PC12 cells transfected with len t i - miR - 133 b or lenti-miR-NC; C) representative images of PCNs transfected with lenti-miR-133b or lenti-miR-NC; D) representative images of axon regeneration in PCNs on CSPG-coated substrate transfected with lentimiR-133b or treated with Y27632, and their negative controls. $\left({ }^{*} \mathrm{p}<0.05\right.$, bar=50 um).
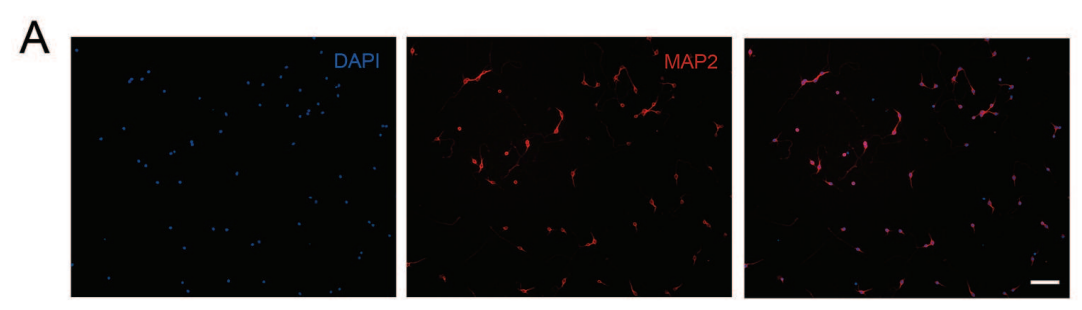

B
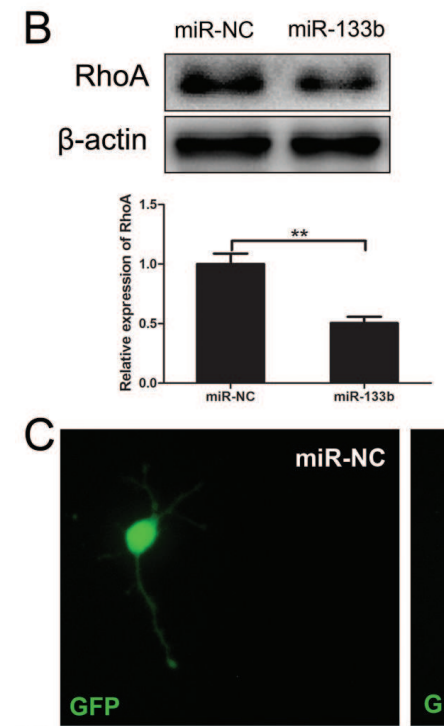

$\mathrm{D}$
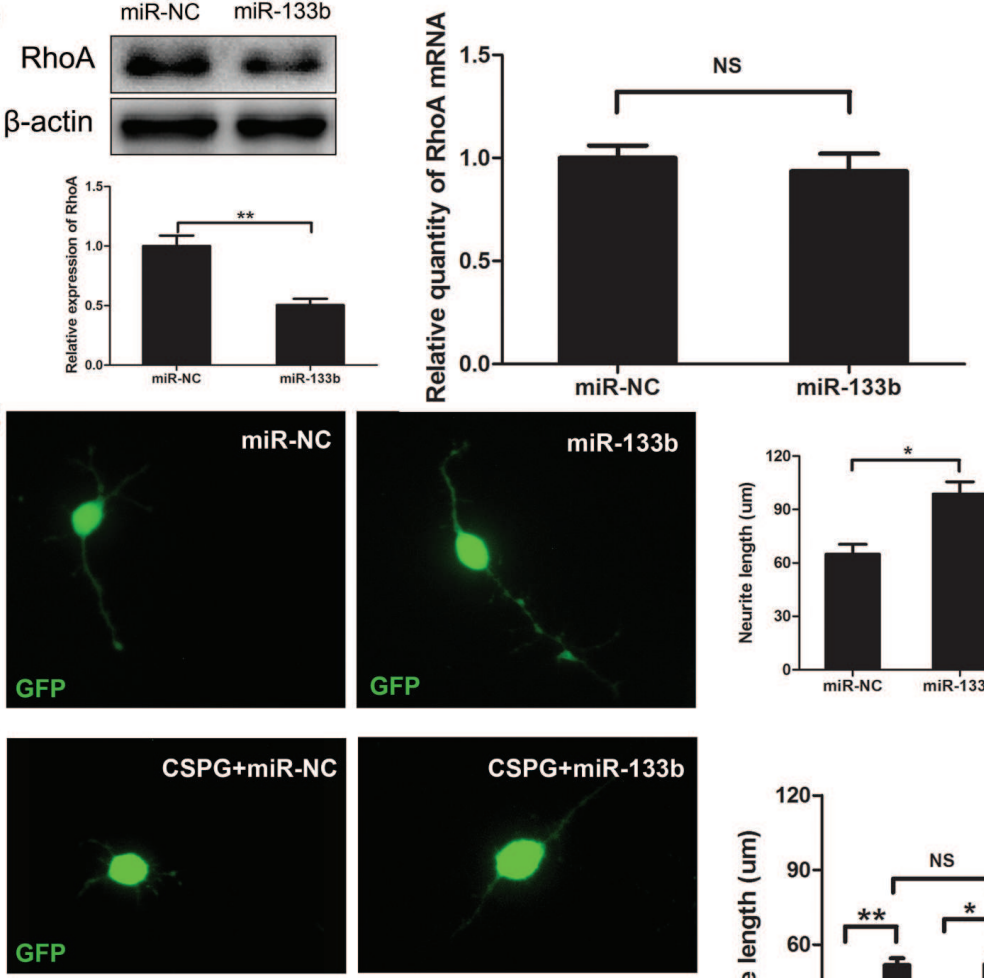

GFP
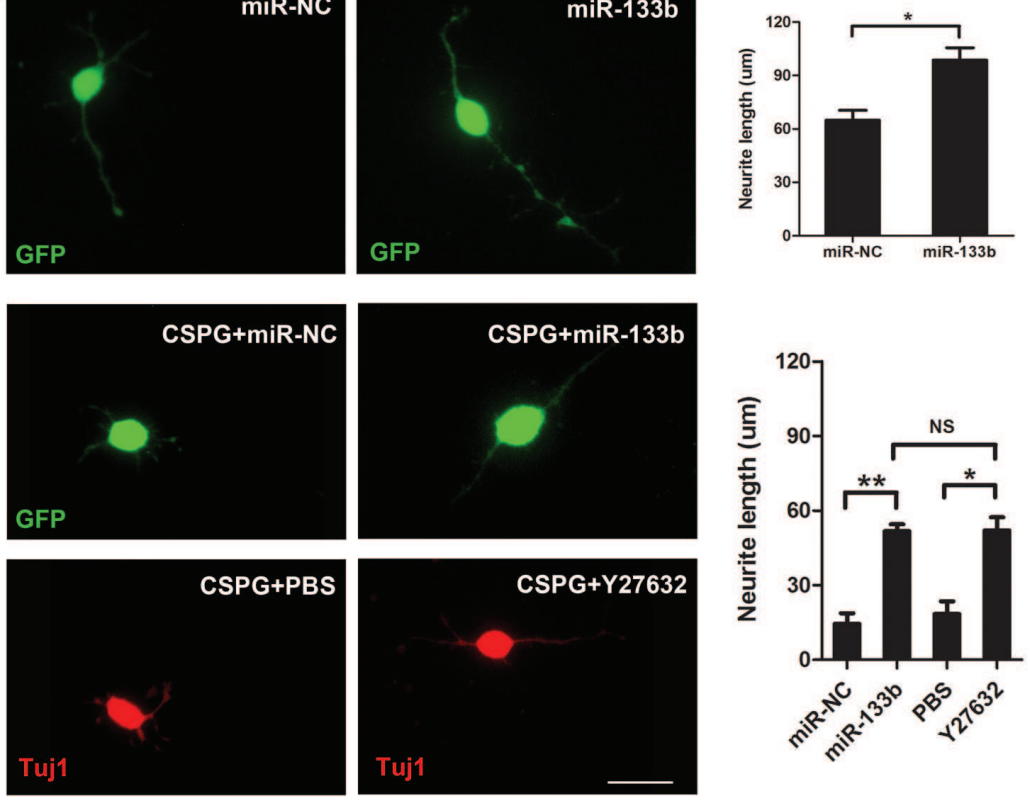

and remarkably stimulated the neurite extension in PC 12 cells. Moreover, overexpression of RhoA was sufficient to attenuate miR-133n induced neurite extension, indicating that miR133b facilitated neurite outgrowth in PC12 cells by targeting RhoA.

We then investigated what signaling pathway was responsible for neurite outgrowth induced by miR-133b. Previous studies demonstrated that positive neurotrophin effects of NGF were attributed to signaling via the Trk family of receptor tyrosine kinases, which further activated several signaling pathways, such as MAPKs and PI3K/Akt pathway [34, 35]. Here, we showed that phosphorylation of ERK1/2 was activation in miR-133b enriched PC12 cells. Moreover, the inhibition of their immediate upstream MEK1/2 kinase by PD98059 diminished neurite outgrowth induced by miR-133b, as well as which induced by NGF. ERK activation has been shown to play a critical role in the neurite outgrowth, since ERK inhibitor PD98059 almost totally blocked NGF-induced neurite outgrowth [36, 37]. In addition, we showed that phosphorylated Akt level was increased in PC12 cells transfected with lentimiR-133b. Moreover, LY294002, an inhibitor of phosphoinositide-3' kinase (PI3K), inhibited 


\section{Cellular Physiology and Biochemistry}

Cell Physiol Biochem 2015;35:246-258

\begin{tabular}{l|l}
\hline DOI: $10.1159 / 000369692$ & (C) 2015 S. Karger AG, Basel
\end{tabular}

\begin{tabular}{l|l} 
Published online: January 09, 2015 & www.karger.com/cpb
\end{tabular}

Lu et al.: MiR-133b Promotes Neurite Outgrowth

miR-133b induced neurite extension, but had no effect on the axonal length induced by NGF. These observations were consistent with findings of Markus A and co-workers [38], who demonstrated that MEK/ERK was both necessary and sufficient for NGF-stimulated axon growth, whereas PI3K/Akt pathway might be not crucial in the process of neurite outgrowth following NGF stimulation [39-41]. Our study also indicated that miR-133b did not enhance p38 phosphorylation, another MAPK family member involving in NGF-induced neurite outgrowth.[42] We further observed that knockdown of RhoA protein by RhoA-specific shRNA increased phosphorylation of Akt and ERK1/2 in PC12 cells, which were consistent with previous reports, indicating that down-regulation of RhoA activated ERK1/2 and Akt in leukaemia and HEK 293E cells [30,31]. Together, these results demonstrated that miR-133b promoted neurite outgrowth via enhancing MEK/ERK and PI3K/Akt pathways by targeting RhoA.

The failure of axon spontaneous regeneration after the CNS injury is partially attributed to the presence of inhibitory molecules in the CNS environment, such as myelin-associated glycoprotein (MAG), Nogo and CSPG [43-45]. RhoA, acting as an intrinsic modulator of axon growth [46, 47]. Some of the Rho/ROCK inhibitors, C3 transferase and Y27632, are sufficient to allow axon regeneration on inhibitory substrates, as well as have beneficial effects in lesion models of the CNS and PNS.[46, 48] As described above, upregulation of miR-133b also promoted axon growth in PCNs by suppression of RhoA. We further investigated whether miR-133b could overcome the inhibitory effect of CSPG on axonal regeneration inhibitors. The results showed that miR-133b, similar to Y27632, was sufficient to promote axon outgrowth of PCNs on CSPG substrates. This observation might contribute to, at least partially, the benefit effects of miR-133b on the functional recovery after spinal cord injury and stroke $[12,14]$.

In conclusion, our observations suggest that miR-133b mediates neuritic outgrowth by suppression of RhoA, thereby activating MEK/ERK and PI3K/Akt pathways in PC12 cells. Additionally, overexpression of miR-133b can overcome axon growth restrictions from CSPG through inhibition of RhoA/ROCK pathway.

\section{Disclosure Statement}

The authors declare no conflict of interest.

\section{Acknowledgements}

This study was supported by grants from the National Natural Science Foundation of China (No. 81171147), "Xingwei Project" Key Personal Medical Research Foundation of Health Department of Jiangsu Province (No. RC201156), "Six Categories of Key Person" Research Foundation of Jiangsu Province (No. 069), Nanjing Medical Science and Technique Development Foundation (No. QKK10194), Program Sponsored for Scientific Innovation Research of College Graduate in Jiangsu Province (No. CXZZ12_0583), and Project Funded by the Priority Academic Program Development of Jiangsu Higher Education Institutions (No. JX10231801). The authors further want to thank Department of Cardiology, The First Affiliated Hospital of Nanjing Medical University.

\section{References}

1 Bartel DP: Micrornas: Target recognition and regulatory functions. Cell 2009;136:215-233.

2 Kosik KS: The neuronal microrna system. Nat Rev Neurosci 2006;7:911-920.

-3 Agostini M, Tucci P, Steinert JR, Shalom-Feuerstein R, Rouleau M, Aberdam D, Forsythe ID, Young KW, Ventura A, Concepcion CP, Han YC, Candi E, Knight RA, Mak TW, Melino G: Microrna-34a regulates neurite outgrowth, spinal morphology, and function. Proc Natl Acad Sci U S A 2011;108:21099-21104. 


\section{Cellular Physiology and Biochemistry}

Cell Physiol Biochem 2015;35:246-258

\begin{tabular}{l|l}
\hline DOI: $10.1159 / 000369692$ & (c) 2015 S. Karger AG, Basel
\end{tabular}

Published onine: January 09, $2015 \quad$ www.karger.com/cpb

Lu et al.: MiR-133b Promotes Neurite Outgrowth

4 Baudet ML, Zivraj KH, Abreu-Goodger C, Muldal A, Armisen J, Blenkiron C, Goldstein LD, Miska EA, Holt CE: Mir-124 acts through corest to control onset of sema3a sensitivity in navigating retinal growth cones. Nat Neurosci 2012;15:29-38.

5 Dajas-Bailador F, Bonev B, Garcez P, Stanley P, Guillemot F, Papalopulu N: Microrna-9 regulates axon extension and branching by targeting map1b in mouse cortical neurons. Nat Neurosci DOI: 10.1038/ nn.3082.

6 Crawford M, Batte K, Yu L, Wu X, Nuovo GJ, Marsh CB, Otterson GA, Nana-Sinkam SP: Microrna 133b targets pro-survival molecules mcl-1 and bcl2l2 in lung cancer. Biochem Biophys Res Commun 2009;388:483-489.

$7 \mathrm{Hu}$ G, Chen D, Li X, Yang K, Wang H, Wu W: Mir-133b regulates the met proto-oncogene and inhibits the growth of colorectal cancer cells in vitro and in vivo. Cancer Biol Ther 2010;10:190-197.

$>8$ Li X, Wan X, Chen H, Yang S, Liu Y, Mo W, Meng D, Du W, Huang Y, Wu H, Wang J, Li T, Li Y: Identification of mir-133b and rb1cc1 as independent predictors for biochemical recurrence and potential therapeutic targets for prostate cancer. Clin Cancer Res 2014;20:2312-2325.

>9 Care A, Catalucci D, Felicetti F, Bonci D, Addario A, Gallo P, Bang ML, Segnalini P, Gu Y, Dalton ND, Elia L, Latronico MV, Hoydal M, Autore C, Russo MA, Dorn GW, 2nd, Ellingsen O, Ruiz-Lozano P, Peterson KL, Croce CM, Peschle C, Condorelli G: Microrna-133 controls cardiac hypertrophy. Nat Med 2007;13:613-618.

-10 Kim J, Inoue K, Ishii J, Vanti WB, Voronov SV, Murchison E, Hannon G, Abeliovich A: A microrna feedback circuit in midbrain dopamine neurons. Science 2007;317:1220-1224.

11 van den Munckhof P, Luk KC, Ste-Marie L, Montgomery J, Blanchet PJ, Sadikot AF, Drouin J: Pitx3 is required for motor activity and for survival of a subset of midbrain dopaminergic neurons. Development 2003;130:2535-2542.

-12 Yu YM, Gibbs KM, Davila J, Campbell N, Sung S, Todorova TI, Otsuka S, Sabaawy HE, Hart RP, Schachner M: Microrna mir-133b is essential for functional recovery after spinal cord injury in adult zebrafish. Eur J Neurosci 2011;33:1587-1597.

13 Liu NK, Wang XF, Lu QB, Xu XM: Altered microrna expression following traumatic spinal cord injury. Exp Neurol 2009;219:424-429.

14 Xin H, Li Y, Liu Z, Wang X, Shang X, Cui Y, Zhang ZG, Chopp M: Mir-133b promotes neural plasticity and functional recovery after treatment of stroke with multipotent mesenchymal stromal cells in rats via transfer of exosome-enriched extracellular particles. Stem Cells 2013;31:2737-2746.

15 Nordman JC, Kabbani N: Microtubule dynamics at the growth cone are mediated by alpha7 nicotinic receptor activation of a galphaq and ip3 receptor pathway. FASEB J 2014;28:2995-3006.

16 Dhami KS, Churchward MA, Baker GB, Todd KG: Fluoxetine and citalopram decrease microglial release of glutamate and d-serine to promote cortical neuronal viability following ischemic insult. Mol Cell Neurosci 2013;56:365-374.

17 Liu Y, Zhang Y, Lin L, Lin F, Li T, Du H, Chen R, Zheng W, Liu N: Effects of bone marrow-derived mesenchymal stem cells on the axonal outgrowth through activation of pi3k/akt signaling in primary cortical neurons followed oxygen-glucose deprivation injury. PLoS One 2013;8:e78514.

18 Murata Y, Constantine-Paton M: Postsynaptic density scaffold sap102 regulates cortical synapse development through ephb and pak signaling pathway. J Neurosci 2013;33:5040-5052.

19 Lin LF, Chiu SP, Wu MJ, Chen PY, Yen JH: Luteolin induces microrna-132 expression and modulates neurite outgrowth in pc12 cells. PLoS One 2012;7:e43304.

20 Hashimoto K, Ishima T: A novel target of action of minocycline in ngf-induced neurite outgrowth in pc12 cells: Translation initiation [corrected] factor eif4ai. PLoS One 2010;5:e15430.

-21 White RE, Giffard RG: Microrna-320 induces neurite outgrowth by targeting arpp-19. Neuroreport 2012;23:590-595.

-22 Dergham P, Ellezam B, Essagian C, Avedissian H, Lubell WD, McKerracher L: Rho signaling pathway targeted to promote spinal cord repair. J Neurosci 2002;22:6570-6577.

23 Zhong SY, Chen YX, Fang M, Zhu XL, Zhao YX, Liu XY: Low-dose levodopa protects nerve cells from oxidative stress and up-regulates expression of pcreb and cd39. PLoS One 2014;9:e95387.

24 Dai A, Sun H, Fang T, Zhang Q, Wu S, Jiang Y, Ding L, Yan G, Hu Y: Microrna-133b stimulates ovarian estradiol synthesis by targeting foxl2. FEBS Lett 2013;587:2474-2482.

-25 Qin W, Dong P, Ma C, Mitchelson K, Deng T, Zhang L, Sun Y, Feng X, Ding Y, Lu X, He J, Wen H, Cheng J: Microrna-133b is a key promoter of cervical carcinoma development through the activation of the erk and akt1 pathways. Oncogene 2012;31:4067-4075. 


\section{Cellular Physiology and Biochemistry}

Cell Physiol Biochem 2015;35:246-258

\begin{tabular}{l|l}
\hline DOI: $10.1159 / 000369692$ & (c) 2015 S. Karger AG, Basel
\end{tabular}

Published onine: January 09, $2015 \quad$ www.karger.com/cpb

Lu et al.: MiR-133b Promotes Neurite Outgrowth

-26 Samuel F, Hynds DL: Rho gtpase signaling for axon extension: Is prenylation important? Mol Neurobiol 2010;42:133-142.

27 Kubo T, Hata K, Yamaguchi A, Yamashita T: Rho-rock inhibitors as emerging strategies to promote nerve regeneration. Curr Pharm Des 2007;13:2493-2499.

28 Read DE, Gorman AM: Involvement of akt in neurite outgrowth. Cellular and molecular life sciences : CMLS 2009;66:2975-2984.

29 Zhou FQ, Snider WD: Intracellular control of developmental and regenerative axon growth. Philos Trans R Soc Lond B Biol Sci 2006;361:1575-1592.

30 Li F, Jiang Q, Shi KJ, Luo H, Yang Y, Xu CM: Rhoa modulates functional and physical interaction between rock1 and erk1/2 in selenite-induced apoptosis of leukaemia cells. Cell Death Dis 2013;4:e708.

-31 Gordon BS, Kazi AA, Coleman CS, Dennis MD, Chau V, Jefferson LS, Kimball SR: Rhoa modulates signaling through the mechanistic target of rapamycin complex 1 (mtorc1) in mammalian cells. Cell Signal 2014;26:461-467.

-32 Montalban E, Mattugini N, Ciarapica R, Provenzano C, Savino M, Scagnoli F, Prosperini G, Carissimi C, Fulci V, Matrone C, Calissano P, Nasi S: Mir-21 is an ngf-modulated microrna that supports ngf signaling and regulates neuronal degeneration in pc12 cells. Neuromolecular Med 2014;16:415-430.

-33 Fu Q, Hue J, Li S: Nonsteroidal anti-inflammatory drugs promote axon regeneration via rhoa inhibition. J Neurosci 2007;27:4154-4164.

-34 Kaplan DR, Miller FD: Neurotrophin signal transduction in the nervous system. Curr Opin Neurobiol 2000;10:381-391.

35 Segal RA, Greenberg ME: Intracellular signaling pathways activated by neurotrophic factors. Annu Rev Neurosci 1996;19:463-489.

-36 Pang L, Sawada T, Decker SJ, Saltiel AR: Inhibition of map kinase kinase blocks the differentiation of pc-12 cells induced by nerve growth factor. J Biol Chem 1995;270:13585-13588.

-37 Kao S, Jaiswal RK, Kolch W, Landreth GE: Identification of the mechanisms regulating the differential activation of the mapk cascade by epidermal growth factor and nerve growth factor in pc12 cells. J Biol Chem 2001;276:18169-18177.

38 Markus A, Zhong J, Snider WD: Raf and akt mediate distinct aspects of sensory axon growth. Neuron 2002;35:65-76.

-39 Obermeier A, Bradshaw RA, Seedorf K, Choidas A, Schlessinger J, Ullrich A: Neuronal differentiation signals are controlled by nerve growth factor receptor/trk binding sites for shc and plc gamma. EMBO J 1994;13:1585-1590.

40 Ashcroft M, Stephens RM, Hallberg B, Downward J, Kaplan DR: The selective and inducible activation of endogenous pi 3-kinase in pc12 cells results in efficient ngf-mediated survival but defective neurite outgrowth. Oncogene 1999;18:4586-4597.

41 Bang OS, Park EK, Yang SI, Lee SR, Franke TF, Kang SS: Overexpression of akt inhibits ngf-induced growth arrest and neuronal differentiation of pc12 cells. J Cell Sci 2001;114:81-88.

42 Huang C, Borchers CH, Schaller MD, Jacobson K: Phosphorylation of paxillin by p38mapk is involved in the neurite extension of pc-12 cells. J Cell Biol 2004;164:593-602.

43 McGee AW, Yang Y, Fischer QS, Daw NW, Strittmatter SM: Experience-driven plasticity of visual cortex limited by myelin and nogo receptor. Science 2005;309:2222-2226.

-44 McKerracher L, David S, Jackson DL, Kottis V, Dunn RJ, Braun PE: Identification of myelin-associated glycoprotein as a major myelin-derived inhibitor of neurite growth. Neuron 1994;13:805-811.

-45 Mukhopadhyay G, Doherty P, Walsh FS, Crocker PR, Filbin MT: A novel role for myelin-associated glycoprotein as an inhibitor of axonal regeneration. Neuron 1994;13:757-767.

-46 Lehmann M, Fournier A, Selles-Navarro I, Dergham P, Sebok A, Leclerc N, Tigyi G, McKerracher L: Inactivation of rho signaling pathway promotes cns axon regeneration. J Neurosci 1999;19:7537-7547.

-47 Sailland J, Tribollet V, Forcet C, Billon C, Barenton B, Carnesecchi J, Bachmann A, Gauthier KC, Yu S, Giguère V, Chan FL, Vanacker JM: Estrogen-related receptor $\alpha$ decreases RHOA stability to induce orientated cell migration. Proc Natl Acad Sci U S A 2014;111:15108-15113.

48 McKerracher L, Higuchi H: Targeting rho to stimulate repair after spinal cord injury. J Neurotrauma 2006;23:309-317. 